DOI: http://dx.doi.org/10.18764/2358-4319.v12n1p227-249

\title{
Literatura com conteúdo(s) matemático(s) na perspectiva do Mateludicando
}

Claudionor Renato da Silva ${ }^{1}$

\section{RESUMO}

Literatura com conteúdo matemático ou conteúdos matemáticos é um conceito desenvolvido a partir de produções nacionais e internacionais na interface matemática/literatura, matemática/ literatura infantil, matemática/histórias infantis. Este conceito permite à abordagem do "MATEludicando" (SILVA, 2015; 2017), de base huizinganiana, fundamentada no lúdico, organizar um checklist com a produção de literatura com conteúdo(s) matemático(s) desenvolvido numa disciplina de Fundamentos e Metodologias de Matemática de um curso de Pedagogia, de uma universidade federal na região norte do país. A problemática instaurada é: dos livros produzidos que elementos do MATEludicando estão aí presentes e quais necessitam ser identificados e aprofundados? Objetiva-se, assim, uma aplicabilidade direta do MATEludicando, com produção de literatura infantil com conteúdo matemático. Segue-se numa abordagem qualitativa de pesquisa com o uso da técnica experimental, segundo Severino (2007). Os resultados indicam algumas pequenas aproximações à abordagem, exigindo um esforço mais concentrado nas pesquisas ainda em andamento. Outro ponto a considerar é a necessidade de aprofundamentos nos elementos do checklist que são norteadores da metodologia de aplicação do MATEludicando na literatura voltada para o ensino-aprendizagem de matemática na educação infantil e anos iniciais do ensino fundamental.

Palavras-chave: MATEludicando. Literatura. Matemática.

1 Doutor em Educação Escolar pela Universidade Estadual Paulista Júlio Mesquita Filho (UNESP/FCLar). Professor e pesquisador na Universidade Federal de Goiás/Regional de Jataí: Curso de Pedagogia e Programa de Pós-Graduação em Educação (PPGE). Membro Associado da ABEC-BRASI (Associação Brasileira de Editores Científicos), da ANPED (Associação Nacional de Pós-Graduação e Pesquisa em Educação) e da ABPN (Associação Brasileira de Pesquisadores Negros) - Área Educação. E-mail: claudionorsil@gmail.com 


\title{
Literature with mathematical content in the perspective of Matheplayful
}

\begin{abstract}
Literature with mathematical (s) content (s) is a concept developed from national and international productions in mathematics interface / literature, math / children's literature, math / children's stories. This concept allows the pedagogical practice approach "MATHEludicando" of huizinganiana basis (SILVA, 2015, 2017), based on the playful, organize an initial checklist from the production of books with literature mathematical (s) content (s) developed in a discipline of fundamental of Mathematics and methodologies of a Faculty of Education, a federal university in the north of the country. The problem is introduced: the produced books MATHEludicando elements are present there and which need to be identified? Thus, a direct applicability of the MATHEludicando with the production of children's literature with mathematical content. It follows a qualitative research approach using the experimental technique, according to Severino (2007). The results indicate some minor approaches to the approach, requiring a more concerted effort still in progress. Another point to consider is the need for deepening the checklist of elements that are guiding of MATHEludicando application methodology in the literature, focusing on the mathematics teaching and learning in early childhood education and early years of elementary school.
\end{abstract}

Keywords: MATHEludicando. Literature. Mathematical.

\section{Literatura con contenido (s) matemático (s) en la perspectiva del Mateludicando}

\section{RESUMEN}

La literatura con contenido matemático o contenidos matemáticos es un concepto desarrollado a partir de producciones nacionales e internacionales en la interfaz matemática / literatura, matemáticas / literatura infantil, matemáticas / historias infantiles. Este concepto permite el abordaje del "MATEludicando" (SILVA, 2015, 2017), de base huizinganiana, fundamentada en el lúdico, organizar un checklist con la producción de literatura con contenido (s) matemático (s) desarrollado en una disciplina de Fundamentos y Metodologías de Matemática de un 
curso de Pedagogía, de una universidad federal en la región norte del país. La problemática instaurada es: ¿qué elementos del MATEludicando de los libros producidos están ahí presentes y cuáles necesitan ser identificados y profundizados? Se pretende, así, una aplicabilidad directa del MATEludicando, con producción de literatura infantil con contenido matemático. Se sigue un abordaje cualitativo de investigación con el uso de la técnica experimental, según Severino (2007). Los resultados indican algunas pequeñas aproximaciones al enfoque, exigiendo un esfuerzo más concentrado en las investigaciones aún en marcha. Otro punto que se considerará es la necesidad de profundizar en los elementos del checklist que son orientadores de la metodología de aplicación del MATEludicando en la literatura volcada para la enseñanza-aprendizaje de matemáticas en la educación infantil y años iniciales de la enseñanza fundamental.

Palabras clave: MATELudicando. La literatura. Matemáticas.

\section{Introdução}

A presente pesquisa é oriunda da abordagem conceitual MATEludicando (SILVA, 2015, 2017), de base filosófica sobre o lúdico, a ludicidade, no referencial de Johan Huizinga, em sua obra Homo Ludens (HUIZINGA, 2012).

Os dados derivam de análises de-produções de livros de literatura com conteúdo(s) matemático(s), elaborados no decurso do componente curricular Fundamentos e Metodologias do Ensino de Matemática, num curso de Pedagogia, de uma universidade do norte brasileiro, no ano de 2015. Estes livros foram voltados para a educação infantil e para os anos iniciais do ensino fundamental ( $1^{\circ}$ ao $\left.3^{\circ} \mathrm{Anos}\right)$. Para o ensino fundamental foi dado destaque às produções digitais do Pnaic nos conteúdos referentes à Matemática (Pacto Nacional pela Alfabetização na Idade Certa) disponíveis no sítio do MEC, neste período.

O MATEludicando está em desenvolvimento pelo autor, desde 2014 e pretende propor aspectos metodoló gicos para a literatura, como um componente de aplicação em sala de aula (SILVA, 2015).

Após esta seção introdutória, o artigo conta com duas seções subsequentes que tratam dos aspectos teóricos conceituais: a primeira sobre a conceituação de literatura com conteúdo(s) matemático(s); 
a segunda, sobre a concepção do MATEludicando como abordagem de prática pedagógica e sobre os contornos que assume na literatura com conteúdos matemáticos, tendo como referencial a obra Homo Ludens, de Johan Huizinga.

Uma seção é destacada para detalhar o método e os procedimentos da pesquisa. Em seguida, apresentam-se os resultados e discussões a partir de um checklist elaborado pelo autor, para associar a literatura com conteúdo(s) matemático(s) na abordagem do MATEludicando. Ao final, são esclarecidas algumas considerações que permitem elucidar as contribuições da pesquisa para a formação inicial de pedagogos(as) que irão ensinar matemática na educação infantil e anos iniciais. As considerações avançam também no sentido de apontar a necessidade de "testagens" destas histórias em salas de aula reais, junto às crianças, evidenciando o elemento 5 do checklist " Ação visível e "palco", ou seja, presença de um público - corporalidades"; contação das histórias com conteúdo(s) matemáticos e problematizações dos saberes e conceitos matemáticos.

\section{Literatura com conteúdo(s) matemático(s)}

A relação entre matemática e literatura já é, há algum tempo, um referencial nacional e internacional. No Brasil, para citar alguns poucos, dentre muitos outros trabalhos, temos Smole; Cândido; Stancanelli (1999), Smole (2004), Oliveira; Passos (2008), Palhares; Azevedo (2010), Souza; Oliveira (2010), Baldow (2012) e Silva (2012).

Alguns autores na vertente internacional serviram de base para a constituição do termo Literatura com Conteúdo(s) Matemático(s) aqui desenvolvido, como: Weltchman-Ticher (1992), Shih; Giorgis (2004), Loureiro (2006), Gáston (2008), Filipe (2012) e Dias (2015).

Oliveira e Passos (2008, p. 320) citam, por exemplo, Aritmética da Emília de Monteiro Lobato em que o autor faz referência à obra $\mathrm{O}$ Homem que Calculava, de Malba Tahan: “[...] através de suas obras mostram-nos que a matemática pode ser ensinada por meio de nossa capacidade imaginativa e criativa de contar histórias".

Literatura com conteúdo(s) matemático(s), definição escolhida pelo autor deste artigo, nas pesquisas metodológicas em andamento, sob a perspectiva do MATEludicando, aproxima-se da conceituação dada por Oliveira e Passos (2008). Neste trabalho, as autoras utilizam o 
termo "histórias infantis com conteúdo matemático" e associam estas histórias à questão do material didático disponível aos professores(as) de matemática ou pedagogos(as) que ensinam matemática nos anos iniciais do ensino fundamental. As autoras, afirmam que:

[..] há necessidade de que o professor construa um repertório de saberes ou desenvolva o que Zabala (1998) chama de pensamento estratégico, necessários à ação docente. Buscando experiências que, de alguma maneira, contribuem para esse desenvolvimento, temos o trabalho de Davis e Krajcik (2005) sobre o que chamam de materiais curriculares educativos, desenvolvidos tendo como referência os estudos sobre aprendizagem da docência. [...] Nesse sentido, a construção de materiais que auxiliem nesse desenvolvimento profissional parece um promissor campo de investigação e de formação. (OLIVEIRA; PASSOS, 2008, p. 318).

A literatura é, portanto, segundo estas autoras, enquanto possibilidade de criação de histórias e enredos com conteúdos matemáticos, uma junção de emotividade, pensamento e criação, fundamentais para a construção da lógica matemática, além, de importante área do conhecimento para práticas interdisciplinares, a partir da Língua Portuguesa.

Estamos a considerar, portanto, não somente uma prática pedagógica aos educandos e educandas, numa perspectiva de educação matemática (alfabetizatória/letrada), mas também de formação professoral nas metodologias diversas da área da Matemática, seja na formação de pedagogos(as), seja na formação de licenciados em matemática ou ciências.

Uma literatura com conteúdo matemático deve atentar ao seguinte fator: o fator educacional, ou, a intencionalidade curricular que permita ao educando associar a matemática, enquanto disciplina, ao mundo constituído e em constante movimento e re-adaptações. Neste sentido, propostas pedagógicas em educação matemática, na utilização da literatura, não podem prescindir, de qualquer tipo de material didático literário, ao contrário, ele deve ser pensado, adequado ao currículo utilizado e, caso não exista o material, haver uma possibilidade de criação e de elaboração deste material, numa perspectiva inovadora educacional, particularmente, em educação matemática, que tenha como perspectiva a alfabetização e letramento nos números e operações, nas formas geométricas e manipulação de objetos matemáticos concretos 
e ideias iniciais de estatística e probabilidades. A literatura infantil é um excelente recurso para estes fins.

Este aspecto é defendido também pelos autores estrangeiros aqui elencados, tanto em Portugal, quanto nas produções de língua inglesa. June L. Gastón, por exemplo, afirma que a literatura com conteúdo matemático fornece elementos sobre ideias matemáticas e, portanto, associadas ao letramento matemático (GÁSTON, 2008). .

Gáston (2008) afirma, utilizando-se de outros estudos, que, por meio da literatura infantil matemática:

- Os estudantes se tornam mais interessados - referência nos estudos de Welchman-Tischler (1992).

- São excelentes aportes para resolução de problemas nas aulas de Matemática - estudos de Jacobs; Rak (1997) e de Melser; Leitze (1999).

- Os estudantes passam a apreciar a matemática, verificando que ela pode ser utilizada na vida real - com base na pesquisa de Herbert; Furner (1997).

- A literatura passa a ser um motivador para aprendizagem em matemática - referência nos estudos de Usnick; Mccarthy (1998).

- Tornam os estudantes, pensadores mais críticos e possibilita que se tornem capazes de conectar ideias matemáticas às experiências pessoais - conforme Murphy (2000).

Citando Welchman-Tischler (1992), Gáston (2008) reproduz os sete diferentes tipos de atividades de matemática com o uso da literatura infantil:

1) atividades que forneçam um contexto ou modelo para entendimento de um conteúdo matemático;

2) atividades de manipulação concreta inicial, como introdutórios a um conteúdo matemático;

3) atividades inspiradoras e engajadoras à uma experiência matemática criativa, próprio do universo infantil;

4) atividades que proponham uma problema matemático interessante e ligado ao cotidiano;

5) atividades que sejam preparatórias para um conceito ou o desenvolvimento de habilidades de cálculo matemático, simples ou complexo; 
6) atividades que desenvolvem e/ou explicam um conceito matemático ou o "passo a passo" de uma habilidade de cálculo a ser aprendida;

7) atividades de revisão de conceitos e/ou habilidades matemáticas.

Dias (2015) articula a literatura no ensino de matemática à interdisciplinaridade, conceituada em sua pesquisa como a relação entre disciplinas. Na Parte III de sua dissertação, Dias (2015) destaca a literatura no ensino de matemática por meio de atividades práticas utilizando-se de obras literárias portuguesas. Este trabalho é um importante guia para atividades na relação literatura/matemática, a partir de obras da literatura infantil clássica, internacional e nacional.

Estes referenciais são a base para a elaboração do conceito "Literatura com conteúdo(s) matemático(s)" que fica assim definido: Literatura com conteúdo(s) matemático(s) são obras originais, criadas por professores em formação inicial ou regentes de sala de aula, com ou sem a ajuda dos seus educandos (as) e que trazem como foco a educação matemática, os conteúdos e conceitos matemáticos voltados à educação infantil e anos iniciais. Esta literatura se caracteriza pela ludicidade huizinganiana na perspectiva da abordagem do MATEludicando. As histórias infantis nestes livros podem conter um ou mais conteúdos de matemática.

Este conceito é essencial para os desdobramentos de estudos no âmbito do MATEludicando, que efetiva a relação matemática/literatura, numa vertente lúdica.

\section{MATEludicando no referencial huizinganiano - foco na literatura, a literatura com conteúdo(s) matemático(s)}
A definição de MATEludicando elaborada por Silva (2015, p. 191) é:

Uma ação de ensino-aprendizagem em Educação Matemática, fundamentada na Filosofia. Uma ação compartilhada e vivenciada entre educadores(as) e educandos(as) infantis, na forma de saberes que focam a emergência do lúdico nas atividades pedagógicas intencionadas e planejadas na educação infantil, de acesso e permanência em momentos de manipulação e abstração de objetos ou símbolos na corporalidade, 
propiciando tanto as primeiras linguagens matemáticas como também as primeiras percepções matemáticas na demonstração de utilidade no dia a dia, de modo que o prazer e a afetividade sejam motores de potencializações de olhares à matemática como um conhecimento acessível, fácil, prazeroso e essencial à vida, por meio do jogo, da brincadeira, das artes cênicas, da música, da dança, da poesia, da literatura, expressões estas e outras possíveis, que, com objetos e corporalidades evocam a matemática, sua presença no mundo físico, sua essência científico-prática.

Partindo desta definição, responde-se a duas perguntas centrais desta subseção: 1) Qual a proposta de Huizinga para a ludicidade na literatura? 2) Se a poética e a literatura nascem do lúdico e se comportam/ aportam no jogo, como esta base teórica huizinganiana da ludicidade pode auxiliar uma proposta de literatura com conteúdo(s) matemático(s) na área da educação matemática, voltada para a educação infantil e anos iniciais?

A resposta para a primeira pergunta pode inicialmente ser dada na afirmação de Huizinga (2012) sobre a presença do elemento lúdico que é inerente à própria natureza da filosofia. O ponto de partida desta natureza se dá "[...] nos próprios diálogos de Platão" (HUIZINGA, 2012, p. 167).

O diálogo continuou sendo, ao longo da história da filosofia, e também da história da matemática, uma forma de pensar os problemas e buscar suas respostas ou soluções, seja por meio de palavras, números, equações, axiomas, teoremas, etc.

Huizinga (2012) afirma que, ao diálogo filosófico "falado" se abre um novo campo do diálogo, aquele que denomina diálogo "escrito", ou diálogo literário, inicialmente, de natureza poética. O literário vem muito tempo depois. Originalmente, a poética (falada) é a que inaugura o diálogo ou o dialógico, na filosofia grega, desprendida da religião, e voltada à arte.

O diálogo é uma forma de arte, uma ficção, dado que evidentemente a verdadeira conversação, por mais requintada que pudesse ser entre os gregos, nunca poderia ter correspondido exatamente à forma do diálogo literário. Nas mãos de Platão, o diálogo é uma coisa leve e aérea, completamente artificial (HUIZINGA, 2012, p.167). 
A "leveza” platônica poética, afirma Huizinga (2012), é de natureza lúdica:

[...] a poiésis é uma função lúdica. Ela se exerce no interior da região lúdica do espírito, num mundo próprio para ela criada pelo espírito, no qual as coisas possuem uma fisionomia diferente da que apresentam na "vida comum", e estão ligadas por relações diferentes das da lógica e da causalidade (HUIZINGA, 2012, p. 133).

Huizinga nos convence que esta poética é abstrativa, mas ainda não é lógica; a poética não está refém da seriedade, pois se configura arte. Como um jogo que se estabelece na abstração lúdica faz emergir assim a literatura, o processo escrito.

A poética vai encontrar sua base na infância ou pelo menos, Huizinga (2012) vai afirmar que o poeta vai buscar sua arte no "mundo" ou territórios da infância, daí as fortes relações entre o lúdico, o brincar, e o jogo. O que isto significa? Significa a possibilidade de se afirmar que a ludicidade, que emerge do jogo poético e se transpõe para o literário está ligada intrinsicamente com o imaginativo da infância, da criação, da brincadeira. A obra literária lúdica apresenta

[...] todas as formas de competição [...]: concursos de insultos, de jactância, a "comparação dos homens", a competição em conhecimentos cosmogônico, a competição pela noiva, o teste de resistência, o ordálio - num jacto ao mesmo tempo selvagem e sóbrio de imaginação poética (HUIZINGA, 2012, p. 134-135).

Apoiando-se em Francis Bacon, Huizinga (2012) afirma que a produção imaginária no jogo, que faz o lúdico emergir, pela literatura, anuncia um olhar do mundo real e atual, mas que anuncia posteriormente "[...] uma sabedoria que virá depois a ser expressa pelas formas lógicas de uma época mais tardia (HUIZINGA, 2012, p. 134)".

Esta época mais tardia se refere tanto à literatura em si, quanto à relação desta com a matemática e, esta particularmente, ao campo da Filosofia.

Outro detalhe importante: a poesia e a literatura não possuem um caráter estritamente estético, ao contrário, tem uma função social, pois diverte, produz arte, produzem enigmas, doutrina/ensina, persua- 
de, propõe adivinhação e, fundamentalmente, é um campo para competição e jogo (HUIZINGA, 2012).

A literatura, num dado momento histórico da filosofia, passa a ser um valioso instrumento do pensamento filosófico. Citando Paul Ricoeur, Figueiredo; Nunes e Nogueira (2014) abordam este momento, o da existência e evidência da literatura na Filosofia. A Literatura era tanto para passatempo (entretenimento), como também para a função de"moralizar", mas, fundamentalmente voltadas para reflexões filosóficas, uma vez que

[...] a literatura é um fenômeno de primeira ordem para o pensamento filosófico. Pode-se afirmar que desde a origem do pensamento ocidental literatura e filosofia caminham juntas, e talvez estejam tão interligadas que seja indecorosos delimitar suas fronteiras (FIGUEIREDO; NUNES; NOGUEIRA, 2014, p. 67).

A literatura é assim, esta intuição criativa, artística no sentido amplo e que antecede a filosofia e depois a ela se junta para refletir sobre o mundo e as coisas.

Os elementos poéticos e literários presentes no jogo, na ludicidade são limites espaço-temporais; é abstração e imaginatividade; ambiente "arrebatador" e envolvente; pode ser celebrado um ambiente sagrado ou festivo; toda ação do "enredo" é marcada por exaltação, seguido de uma tensão para culminar em "[...] um estado de alegria e de distensão (HUIZINGA, 2012, p. 147)".

Mas, e o lúdico e a ludicidade, particularmente? Aqui vale a pena lembrar, como nos apresenta Huizinga (2012), que nas línguas romana e grega, lúdico, brincar e jogo tinham o mesmo sentido; eram a mesma coisa, não havia separação entre elas. Contudo, no ocidente, e com a escolarização, jogo, brincar e lúdico foram fragmentadas: jogo passou a ser algo como que sério e atribuído aos adultos; ludicidade e brincadeira, algo menor, infantil, voltado ao lazer, algo não sério.

As crianças levam muito a sério o jogo de engajar-se em uma atividade de aprendizagem e que, portanto, a filosofia estava certa quando propunha que jogo, ludicidade e o brincar estão diretamente associados e são partes intrínsecas do homo ludens; ele não é apenas o homo fabris, modelo este adotado pela escola no século XVIII e que ainda sobrevive em nossos dias. 
Com estas considerações se responde a segunda pergunta desta subseção: esta base teórica huizinganiana da ludicidade permite a afirmação e a defesa de que a interface literatura/matemática é possível numa proposta de educação matemática voltada para a educação infantil e anos iniciais. Referente à proposta das bases huizinganianas para a literatura com conteúdo(s) matemático(s), focando o lúdico, temos as seguintes assertivas:

- A proposta huizinganiana se aplica, inicialmente, numa visão de lúdico que emerge do imaginativo, abstratividade, seja na construção de histórias com conteúdos matemáticos ou na análise de obras literárias já existentes.

- Em segundo lugar a proposta huizinganiana recupera a filosofia poética, literária e, portanto, associa a matemática e a linguagem falada e escrita. Sendo a leitura uma das maiores dificuldades das crianças nas aulas de matemática, aposta-se no modelo do MATEludicando como recurso pedagógico que, no caso da literatura, incentiva o raciocínio matemático, a abstração, por meio da leitura e do ouvir uma obra literária, conformando-se às pesquisas internacionais e nacionais desde os anos 1990.

- Em terceiro lugar, Huizinga nos permite construir um modelo de prática pedagógica ou uma abordagem (o MATEludicando) em que a literatura, o lúdico, são pontos de partida, processos e pontos de chegada, num ponto fixo e comum, objeto da prática, a criança.

Estas assertivas estarão presentes na apresentação dos resultados da pesquisa que analisa dois livros com conteúdo(s) matemático(s) produzidos no âmbito de uma disciplina de Fundamentos e Metodologias de Matemática de um curso de Pedagogia do norte do Brasil.

\section{Metodologia e procedimentos}

A pesquisa tem uma abordagem qualitativa com o uso da técnica experimental, segundo Severino (2007), caracterizada, como se segue na citação: 
rimental [...] onde são criadas condições adequadas para seu tratamento. Para tanto, o pesquisador seleciona determinadas variáveis e testa suas relações funcionais, utilizando formas de controle (SEVERINO, 2007, p. 123).

Nas Ciências Naturais, bem como no Ensino de Matemática, particularmente, na Educação Matemática, numa perspectiva de inovação educacional, tal como é a proposta do MATEludicando $(2015 ; 2017)$ esta técnica, a experimental é muito propícia.

$\mathrm{Na}$ etapa das horas voltadas à prática (carga horária prática) do componente curricular Fundamentos e Metodologias do Ensino de Matemática, de um curso de Pedagogia, durante o primeiro semestre de 2015, se propôs, a partir do MATEludicando - abordagem de conceituação criada pelo autor (SILVA, 2015; 2017) - a elaboração de livros com conteúdo(s) matemáticos(s).

Os estudantes então se reuniram em grupos e passaram à elaboração dos livros, tendo como referencial a abordagem do MATEludicando. Cada grupo desenvolveu um conteúdo da matemática voltado à educação infantil e anos iniciais do ensino fundamental: números e operações; figuras e formas; grandezas e medidas e tratamento da informação. Serviram como referencial teórico-metodológico os livros digitais do Pnaic - Pacto Nacional pela Alfabetização na Idade Certa - disponíveis no sítio do Ministério da Educação.

Foram produzidos seis livros: Sabrina e as formas geométricas; Brincando com números e operações nas séries iniciais; $\mathrm{O}$ segredo de uma bela receita é suas medidas; $\mathrm{O}$ atleta que multiplicava; Vovó Rosa em compras e Um dia na casa da vovó Beatriz: o encontro com números e operações.

A análise dos livros se concentrara numa pergunta que é central na apresentação dos resultados e discussão: Que aspectos do MATEludicando estão presentes nestas produções, considerando que se tratam de livros com conteúdo(s) matemático(s)?

Para esta questão foi organizado pelo autor um checklist inicial, como guia para a verificação/avaliação dos livros produzidos com conteúdos matemáticos, na perspectiva do MATEludicando (Quadros 1 e 2). A seguir os resultados e discussão de duas obras produzidas. 


\section{A produção de livros com conteúdo(s) matemático(s)}

Para o espaço deste artigo será analisado brevemente os livros "Sabrina e as formas geométricas" e "Um dia na casa da vovó Beatriz: o encontro com números e operações".

\section{Sabrina e as formas geométricas}

Alguns aspectos gerais da produção:

- O livro se encaixa no conceito "Literatura com conteúdo(s) matemático(s)".

- O livro tem uma riqueza de desenhos e cores com detalhes às texturas, o que permite o tato para envolvimento na história.

- Traz o imaginativo infantil: a associação dos brinquedos infantis com as figuras geométricas; a associação da matemática com o dia a dia, na forma de perguntas ao pensamento, buscando sistematizações conceituais em matemática.

Alguns fragmentos da obra. Fragmento 1:

Sabrina é uma garota muito esperta e curiosa, sempre questiona o porquê das coisas e se encanta com cada aprendizado. Aprender as figuras geométricas foi um encanto, porém, encontrou algumas dificuldades na compreensão dos conteúdos. Por isso, ao chegar em casa, pensava, pensava... (p.1).

Fragmento 2:

Neste parque, Sabrina começou a imaginar a roda gigante, o balanço, chapéu mexicano, gangorra, etc. Como se pareciam com as figuras geométricas que estava aprendendo na escola (p.2).

Fragmento 3:

Deste dia em diante passaram a brincar juntos no parque todas as tardes. Um dia Sabrina falou para Rafael suas dúvidas sobre as figuras geométricas (p.6).

O Quadro 1 apresenta justificativas/observações sobre a obra, na perspectiva do MATEludicando. 
Quadro 1 - Checklist criado para a abordagem do MATEludicando

\begin{tabular}{|c|c|c|c|}
\hline \multicolumn{2}{|r|}{ Elementos } & \multirow{2}{*}{\begin{tabular}{|c|}
$\begin{array}{c}\text { Sim/Não/ } \\
\text { Parcial }\end{array}$ \\
Não
\end{tabular}} & \multirow{2}{*}{\begin{tabular}{|l|} 
JUSTIFICATIVAS/OBSERVAÇÕES \\
Este elemento é ausente na narrativa.
\end{tabular}} \\
\hline 1 & $\begin{array}{l}\text { Evocação do jogo, o jogo mate- } \\
\text { mático. }\end{array}$ & & \\
\hline 2 & $\begin{array}{l}\text { Presença forte da oralidade e a } \\
\text { contribuição para o desenvol- } \\
\text { vimento em Língua Portuguesa } \\
\text { (língua materna) e a linguagem } \\
\text { científica matemática infantil } \\
\text { - Metodologia do "pergunta-res- } \\
\text { ponde". }\end{array}$ & Parcial & $\begin{array}{l}\text { Elemento que apenas se configura na conversa } \\
\text { entre os dois amigos que se encontram no } \\
\text { parque e falam sobre o que aprenderam sobre } \\
\text { figuras geométricas na escola. É necessário } \\
\text { aprofundar e evidenciar o "pergunta-responde". }\end{array}$ \\
\hline 3 & $\begin{array}{l}\text { Exploração da lógica matemática, } \\
\text { articulada assim, ao elemento } \\
\text { anterior. No caso da literatura, } \\
\text { da poesia e da prosa: o diálogo } \\
\text { literário transposto para o diálogo } \\
\text { conversatório. }\end{array}$ & Parcial & $\begin{array}{l}\text { Esta dialogicidade e lógica é apenas explorado } \\
\text { no aspecto do pensamento em que Sabrina faz } \\
\text { associações entre as figuras geométricas planas } \\
\text { e o que encontra no parque, no caso, os brin- } \\
\text { quedos que lembram figuras geométricas. }\end{array}$ \\
\hline 4 & $\begin{array}{l}\text { Presença constante da dúvida da } \\
\text { dúvida e do infinito das possibili- } \\
\text { dades que emergem do texto ou } \\
\text { da apresentação cênica, verbal, } \\
\text { dança ou música. }\end{array}$ & Não & Elemento ausente. \\
\hline 5 & $\begin{array}{l}\text { Ação visível e "palco", ou seja, } \\
\text { presença de um público - corpo- } \\
\text { ralidades. }\end{array}$ & Não & Elemento ausente. \\
\hline 6 & $\begin{array}{l}\text { Presença de valores e crenças cul- } \\
\text { turais locais, regionais e nacionais. }\end{array}$ & Não & Elemento ausente. \\
\hline 7 & $\begin{array}{l}\text { Evocação da Razão Filosófica, ou } \\
\text { seja, evocação de atitudes filosófi- } \\
\text { cas a partir da Matemática. }\end{array}$ & Parcial & $\begin{array}{l}\text { "[...] encontrou algumas dificuldades na } \\
\text { compreensão dos conteúdos. Por isso, } \\
\text { ao chegar em casa, pensava, pensava... } \\
\text { (p.1). } \\
\text { Sabrina começou a imaginar a roda } \\
\text { gigante, o balanço, chapéu mexica- } \\
\text { no, gangorra, etc. Como se pareciam } \\
\text { com as figuras geométricas que estava } \\
\text { aprendendo na escola (p.2). } \\
\text { A evocação filosófica está presente na narrati- } \\
\text { va. Ela precisa ser potencializada interligando } \\
\text { os conteúdos matemáticos e o pensamento } \\
\text { filosófico muito bem elucidado na história. }\end{array}$ \\
\hline 8 & $\begin{array}{l}\text { Abertura ao imaginativo, à cria- } \\
\text { ção, à abstração. }\end{array}$ & Parcial & $\begin{array}{l}\text { O que falta é uma mediação para que o pensa- } \\
\text { mento e o imaginativo de Sabrina encontrem } \\
\text { aportes nos conteúdos matemáticos. }\end{array}$ \\
\hline
\end{tabular}

Fonte: Elaborado pelo autor. 
Se apresenta, a seguir, o segundo livro produzido e na sequência, uma análise conjunta das duas obras quanto a elementos do MATEludicando presentes e aqueles ainda ausentes, indicando novos caminhos da pesquisa em andamento.

Um dia na casa da vovó Beatriz: o encontro com números e operações

Alguns aspectos gerais da produção:

- O livro também se encaixa no conceito de "Literatura com conteúdo(s) matemático(s)".

- Os desenhos do livro, criados pelos estudantes são muito criativos, coloridos e cheio de detalhes que se interligam a construção textual e ao enredo da história.

- A produção desenvolve bem a ideia de sequência numérica e operações.

- O brincar é um pano de fundo constante nas páginas da produção deste livro desenvolvido pelos estudantes.

Fragmento 1:

Para Lucas, ela pediu que pegasse 5 laranjas na cesta de frutas para fazer o suco.

Para Vitória, que pegasse 4 copos de plástico dentro do armário.

E para Pedro, que pegasse 2 pacotes de bolacha na dispensa (p.6).

Fragmento 2:

Lucas distribuiu as peças do dominó igualmente entre ele e seus primos. E começou o jogo.

- Vai, sua vez Vitória! Disse Pedro.

- E o que faço agora? Perguntou Vitória.

- Conta aqui! 1,2,3, então você tem que procurar suas peças, uma que tem apenas 3 bolinhas. Explicou Lucas.

- 1,2,3,4... essa não dá, 1,2,3... essa aqui! Exclamou Vitória (p. 10).

Fragmento 3:

Terminando o jogo de dominó, os três foram pular corda. 
- Vamos ver quem pula mais? Disse Vitória.

- Então vamos, eu conto! Falou Lucas.

- 1,2, 3, 4,5,6,7,8,9,10,11,12... Errou! Agora é minha vez! Disse Pedro (p.12).

Fragmento 4:

- Agora vamos para o jogo da memória! Exclamou Pedro.

- Esse jogo da memória é diferente, você tem que pegar pares que tenham a mesma quantidade, por exemplo, 3 estrelas. Explicou Vovó Beatriz.

- Eu começo. Disse Vitória (p. 18).

A partir do checklist do Quadro 2 se analisa os elementos do MATEludicando presentes na obra.

\section{Uma breve análise de ambas as obras}

As obras ainda não contemplam todos os elementos huizinganianos. Neste sentido, a única forma de análise é considera-las, neste momento, para este artigo, conjunta e não separadamente.

Este checklist é fundamental para a construção de obra literária com conteúdo(s) matemático(s), sob a perspectiva de Huizinga (2012). Contudo, apresenta elementos centrais como: a evocação do jogo, oralidade e a lógica matemática.

No livro 1 é realizada a associação entre os conteúdos aprendidos em matemática e os brinquedos do parque. Este alinhamento ao dia a dia, como defende Welchman-Ticher (1992), é crucial numa literatura com conteúdo(s) matemático(s). Já o livro 2 não traz este destaque.

Entende-se e defende-se, portanto, a literatura como recurso pedagógico ou recurso didático, ou ainda, recurso para a prática, que, independente da nomenclatura dada, segundo Silva (2013) se caracteriza como

[...] um veículo de sondagem sobre o andamento da situação didática. Essa é uma forma de expansão de competências de argumentação e raciocínio matemático. O recurso, como facilitador do trabalho docente e do processo de aprendizagem do discente ( $p$. 144). 
QUADRO 2 - Checklist da obra Um dia na casa da vovó Beatriz: o encontro com números e operações

\begin{tabular}{|c|c|c|c|}
\hline \multicolumn{2}{|r|}{ Elementos } & \multirow{2}{*}{$\begin{array}{l}\text { Sim/Não/ } \\
\text { Parcial }\end{array}$} & \multirow{2}{*}{$\begin{array}{l}\text { JUSTIFICATIVAS/OBSERVAÇõES } \\
\text { Em todas as atividades desenvolvidas na história há a } \\
\text { evocação do jogo matemático, por exemplo: } \\
\text { "Lucas distribuiu as peças do dominó igualmente entre } \\
\text { ele e seus primos. E começou o jogo" (p. 10). }\end{array}$} \\
\hline 1 & $\begin{array}{l}\text { Evocação do jogo, o jogo mate- } \\
\text { mático. }\end{array}$ & & \\
\hline 2 & $\begin{array}{l}\text { Presença forte da oralidade e a } \\
\text { contribuição para o desenvolvimen- } \\
\text { to em Língua Portuguesa (língua } \\
\text { materna) e a linguagem científica } \\
\text { matemática infantil - Metodologia } \\
\text { do "pergunta-responde". }\end{array}$ & Sim & $\begin{array}{l}\text { Exploram-se muitos diálogos. As crianças com a avó } \\
\text { dialogam o tempo todo e durante os jogos/brincadeiras } \\
\text { que desenvolvem ao longo da história. 0"pergunta-res- } \\
\text { ponde" é recorrente nos diálogos. }\end{array}$ \\
\hline 3 & $\begin{array}{l}\text { Exploração da lógica matemática, } \\
\text { articulada assim, ao elemento } \\
\text { anterior. No caso da literatura, da } \\
\text { poesia e da prosa: o diálogo literário } \\
\text { transposto para o diálogo conver- } \\
\text { satório. }\end{array}$ & Sim & $\begin{array}{l}\text { Os primos aprendem a brincar juntos. É demonstrado } \\
\text { na história que um ajuda } 0 \text { outro a construir a ideia } \\
\text { matemática do cálculo. Se vê isto no jogo de dominó: } \\
\text { - E o que faço agora? Perguntou Vitória. } \\
\text { - Conta aqui! 1,2,3, então você tem que procurar suas } \\
\text { peças, uma que tem apenas } 3 \text { bolinhas. Explicou Lucas. } \\
\text { - 1,2,3,4... essa não dá, 1,2,3... essa aqui! Exclamou } \\
\text { Vitória (p. 10). }\end{array}$ \\
\hline 4 & $\begin{array}{l}\text { Presença constante da dúvida da } \\
\text { dúvida e do infinito das possibili- } \\
\text { dades que emergem do texto ou da } \\
\text { apresentação cênica, verbal, dança } \\
\text { ou música. }\end{array}$ & Não & 0 texto não apresenta este elemento. \\
\hline 5 & $\begin{array}{l}\text { Ação visível e "palco", ou seja, } \\
\text { presença de um público - corpo- } \\
\text { ralidades. }\end{array}$ & Não & $\begin{array}{l}\text { Seria necessária a leitura (contação) e o compartilhar } \\
\text { da história, bem como a organização de um roteiro de } \\
\text { atividade a ser aplicada junto às crianças. }\end{array}$ \\
\hline 6 & $\begin{array}{l}\text { Presença de valores e crenças cultu- } \\
\text { rais locais, regionais e nacionais. }\end{array}$ & Não & Ausência deste elemento. \\
\hline 7 & $\begin{array}{l}\text { Evocação da Razão Filosófica, ou } \\
\text { seja, evocaçãa de atitudes filosóficas } \\
\text { a partir da Matemática. }\end{array}$ & Parcial & $\begin{array}{l}\text { Elemento ausente, porém, é dado alguns indícios } \\
\text { quando se tem uma dúvida sobre como contar, mas não } \\
\text { a ponto de se evidenciar este aspecto do pensamento } \\
\text { filosófico. Matthew Lipman e Walter Cohan seriam } \\
\text { importantes referenciais para este elemento na propos- } \\
\text { ta deste checklist; eles desenvolvem estudos sob o } \\
\text { título: "Filosofia para Crianças". }\end{array}$ \\
\hline 8 & $\begin{array}{l}\text { Abertura ao imaginativo, à criação, } \\
\text { à abstração. }\end{array}$ & Parcial & $\begin{array}{l}\text { A sequência da narrativa aparenta um direcionamento, } \\
\text { um foco, seja pela avó Beatriz, seja por uma das crian- } \\
\text { ças. E as crianças não reinventam o jogo. }\end{array}$ \\
\hline
\end{tabular}

FONTE: Elaborado pelo autor. 
Autores elencados na seção Literatura com conteúdo(s) matemático(s) como Oliveira e Passos (2008), Gáston (2008) e Dias (2015) também corroboram para este aspecto do recurso, ampliando nossa visão quanto ao fato da literatura propiciar interdisciplinaridade a partir da matemática.

Algumas ações para aqueles elementos ausentes nestas obras, apontados no checklist:

- Elemento 4: nas literaturas produzidas esta evocação da dúvida ficou ausente e poderia ser explorada a partir da possibilidade, por exemplo, na história 2, em se perguntar porquê as regras do jogo de dominó eram daquela forma e qual seria a possibilidade desta regras serem mudadas. Dúvida e convencimento era o grande papel do "jogo" filosófico. A literatura tem todo este potencial para os processos de ensino-aprendizagem em matemática, junto às crianças.

- Elemento 5: este elemento faz parte das "testagens" das histórias em sala de aula, com as crianças pequenas. A máxima de Huizinga (2012, p. 57) é válida na história da filosofia: "o sentimento de prazer ou de satisfação aumenta com a presença de espectadores". Os grandes pensadores e oradores gregos primavam pela oratória e pelo convencimento público.

- Elemento 6: Para o contexto do norte brasileiro, as histórias analisadas não trouxeram estes elementos. $O$ enredo permite um re-olhar e a inserção dos valores culturais locais, principalmente aquelas associações possíveis entre os conhecimentos matemáticos e a realidade vivida pelos educandos(as) infantis. Afirma Huizinga (2012, p. 229): "Cada vez mais fortemente se nos impõe a triste conclusão de que o elemento lúdico da cultura se encontra em decadência desde o século XVIII, época em que florescia plenamente". Diante disto, o esforço por histórias na relação literatura/matemática, que dê um enfoque à cultura local é indispensável, necessário e urgente.

- Elemento 7: Evocação da Razão Filosófica, ou seja, evocação de atitudes filosóficas a partir da Matemática; estímulo ao pensar e ao verbalizar o pensamento. Matthew Lipman, Walter Cohan e Edgar Morin seriam importantes referenciais para este elemento na proposta deste checklist; estes autores desenvolvem estudos no campo da Filosofia, da Educação e a Infância. Uma 
das formas da construção do pensamento filosófico ou da reflexão filosófica para Huizinga (2012, p. 179) é

A antilogia, ou raciocínio duplo, era uma das preferidas dos sofistas. Além de abrir um vasto campo para o jogo, esta forma permitia-lhes exprimir a eterna ambiguidade de todos os juízos formulados pelo espírito humano: tudo pode ser apresentado de duas maneiras opostas. E efetivamente aquilo que conserva relativamente pura e legítima a arte de ganhar com as palavras é seu caráter lúdico).

Ainda considerando o Elemento 7, Edgar Morin, em "A cabeça-bem feita" (Morin, 2011, p. 51) coloca a questão da razão filosófica como um desafio à escola, um desafio de se tornar uma "escola da compreensão" buscando e efetivando uma tal "iniciação à lucidez". Desta forma, para Edgar Morin (2011, p.50)

A literatura "é a única que sabe representar e elucidar as situações de incomunicabilidade, de fechamento em si, quiproquós cômicos ou trágicos. O leitor descobre também as causas dos malentendidos e aprende a compreender os incompreendidos" [...]

Em conjunto estes elementos ausentes nas histórias demonstram a dificuldade de se construírem literatura(s) com conteúdo(s) matemática(s) na perspectiva do MATEludicando. Não basta imaginar e criar as histórias, estas histórias seguem um caminho filosófico, que é sua base. Desta forma, pode-se enquadrar o MATEludicando não apenas na campo da história da filosofia, mas também no campo da filosofia da matemática.

Concorda-se com Morin (2011), que este exercício da "iniciação à lucidez" que cabe neste Elemento 7, e que esteve ausente nas histórias, é um exercício que deve acontecer desde a educação infantil, em que "[...] nenhum conhecimento possa dispensar a interpretação (p. 52)".

\section{Considerações finais para continuidade da pesquisa}

A próxima etapa da pesquisa é a "testagem" destas literaturas em aulas de matemática, na educação infantil e anos iniciais do ensino fundamental, em que se procura evidenciar elementos do checklist, principalmente o elemento 5: Ação visível e "palco", ou seja, presença de um público - corporalidades. Mas o mais importante é que tais "testagens" 
tragam contribuições à sala de aula e à prática de professores que ensinam matemática nos primeiros anos de escolarização.

Os livros produzidos estarão compondo um livro sob o tema do MATEludicando e estarão disponíveis no Laboratório de Práticas Pedagógicas da instituição. Está em construção também um guia de aplicação desta literatura, sob a perspectiva do MATEludicando.

A pesquisa até aqui empreendida traz contribuições ao ensino de matemática na educação infantil e anos iniciais. A primeira contribuição é que apresenta uma abordagem de lúdico outra, fora da psicologia, ou seja, apresenta uma abordagem no interior da história da filosofia que recupera os aspectos não só da ludicidade, do brincar e do jogo, mas, sobretudo, da recuperação da estética na educação e na sociedade contemporânea; apresenta um recurso, já comprovado cientificamente na literatura internacional e nacional, nas interfaces matemática/literatura e literatura/ matemática.

A segunda contribuição é que permite, na graduação em pedagogia, ser trabalhado, nas horas práticas da disciplina de matemática, materiais originais, criativos em literatura, que proporcionam aos formandos encontrarem elementos da ludicidade para o letramento matemático na educação infantil e anos iniciais; o material elaborado subsidia práticas de elaboração de Projetos de Estágio e também de práticas pedagógicas nos programas desenvolvidos pela universidade como o Pibid (Programa Institucional de Bolsa de Iniciação à Docência) e o Prodocência (Programa de Consolidação das Licenciaturas).

Uma etapa interessante e imprescindível desta pesquisa e também destes livros produzidos será a submissão destes livros a professores de matemática, formados em matemática para uma avaliação mais técnica dos conteúdos e conceitos matemáticos.

Vale uma última consideração: a literatura é uma das vertentes de aplicação do MATEludicando (SILVA, 2015). Há um grande desafio referente à abordagem: além de melhoramentos conceituais e do checklist aqui organizado, tem-se o desafio da validação tanto da abordagem teórica quanto da aplicabilidade em sala de aula, no desenvolvimento dos saberes e conteúdos matemáticos, na educação infantil e anos iniciais do ensino fundamental. Ademais, seguem os desafios de serem desenvolvidas outras vertentes de aplicabilidade e "testagem" em sala de aula do MATEludicando: no teatro, na música, em contos, poesias e oralidades diversas. 


\section{Referências}

BALDOW, R. . Diálogo lúdico da literatura e a matemática. Recife: CEL, 2012

DIAS, K. .P. . A interdisciplinaridade: a literatura como veículo para a aprendizagem da matemática. 165f. Dissertação - Mestrado em Ensino de Educação Pré-Escolar e Ensino do $1^{\circ}$ Ciclo do Ensino Básico. Universidade de Trás-os-Montes e Alto Douro, Escola de Ciências Humanas e Sociais, Departamento de Educação e Psicologia: Vila Real, Portugal, 2014.

FIGUEIREDO, A.T.M.; NUNES, T.G.S.; NOGUEIRA, M.S.M. O falecido Mattia Pascal: conexões entre literatura e filosofia na obra de Luigi Pirandello. Revista Letras, Curitiba, n. 89, p. 61-77, jan./jun., 2014.

GÁSTON, L.L.. A review and na update on using children's literature to teach mathematics. Using Literature to teach math, 1, 1-13, 2008.

HEBERT, T. ; FURNER, J. High ability students overcome math anxiety through bibliotherapy. Journal of Secondary Gifted Education, 8 (4), 164-78, 1997.

HUIZINGA, J. . Homo ludens: o jogo como elemento da cultura. 7. ed. São Paulo: Perspectivas, 2012.

JACOBS, A.; RAK, S. Mathematics and literature - A winning combination. Teaching Children Mathematics, 4 (3), 156-57, 1997.

LOUREIRO, C. Os livros de historias e a Matemática. Actas Profmat, Associaçao de Professores de Matemática, Lisboa: APM, 2006.

MARCONI, M.A. ; LAKATOS, E.M. Fundamentos de metodologia científica. 5. ed. São Paulo: Atlas, 2003.

MELSER, N.; LEITZE, A. Connecting Language Arts and Mathematical Problem Solving in the Middle Grades. Middle School Journal, 31 (1), 48-54, 1999.

MORIN, E. A cabeça bem-feita. Repensar a reforma, reformar o pensamento. Rio de Janeiro: Bertrand Brasil, 2011.

MURPHY, S. J. Children's books about math: Trade books that teach. New Advocate, 13 (4), 365-74, 2000. 
OLIVEIRA, R. M. M. A. ; PASSOS, C. L. B. . Promovendo o desenvolvimento profissional na formação de professores: a produção de histórias infantis com conteúdo matemático. In: Ciência e Educação, v. 14, nº 2, p. 315330, 2008.

PALHARES, P.; AZEVEDO, F.. Uma proposta de integração entre a matemática e a literatura infantil em contexto de jardim de infância. REVEMAT, Revista Eletrônica de Educação Matemática. Florianópolis, v. 05, n.1, p. 15-24, 2010.

SEVERINO, A.J. Metodologia do trabalho científico. 23. ed. São Paulo: Cortez, 2007.

$\mathrm{SHIH}, \mathrm{J}$; GIORGIS, C. Building the mathematics and literature connection through children's responses (opens in a new window). Teaching Children Mathematics, 10(6), 328-333, 2004.

SILVA, A. C. . Literatura Infantil e a formação de conceitos matemáticos em crianças pequenas. Ciências \& Cognição, v. 17 (1), 37-57, 2012.

SILVA, C.R. Educação Matemática, Didática e Formação de Professores. Um diálogo com licenciandos em pedagogia e matemática. Jundiaí, SP: Paco, 2013.

Mateludicando na educação infantil: um modelo de prática pedagógica para crianças pequenas. Revemat, Florianópolis (SC), v. 10, n. 1, p. 183-198, 2015.

(org.). MATEludicando. Volume 1. Ensaios sobre filosofia, matemática e ludicidade. Curitiba: Appris, 2017.

SMOLE, K.C.S.; CÂNDIDO, P. STANCANELLI, R. Matemática e literatura infantil. (Coleção Apoio). Belo Horizonte: Lê, 1999.

SMOLE, K.C.S.; et al. Era uma vez na matemática: uma conexão com a literatura infantil. São Paulo: CAEM/IME/USP, 2004.

SMOLE, K.C.S.; et al. A matemática na educação infantil: a teoria das inteligência múltiplas na prática escolar. Porto Alegre: Artes Médicas, 2000.

SOUZA, A.P.G; OLIVEIRA, R.M.M.A. Articulação entre literatura infantil e matemática: intervenções docentes. Bolema, Rio Claro (SP), v. 23, n 37, p. 995-75, dez., 2010. 
USNICK, V. ; MCCARTHY, J. Turning adolescents onto mathematics through literature. Middle School Journal, 29 (4), 50-54, 1998.

WELCHMAN-TICHER, R. How to use children's literature to teach mathematics. REston: NCTM, 1992.

Recebido em: agosto/2018

Aprovado em: dezembro/2018 